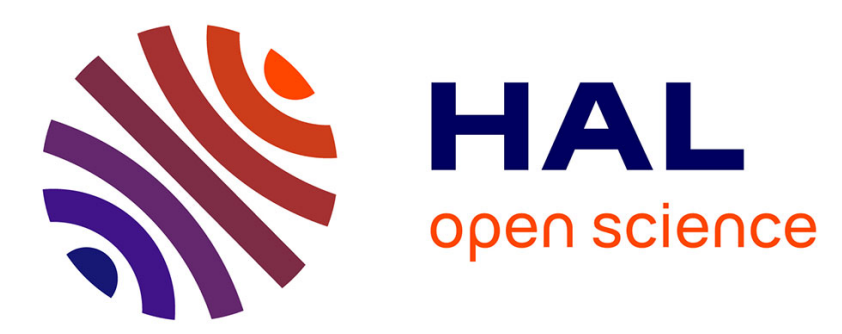

\title{
Experimental and numerical analysis of the selective laser sintering (SLS) of PA12 and PEKK semi-crystalline polymers
}

\author{
Patrice Peyre, Yann Rouchausse, Denis Defauchy, Gilles Regnier
}

\section{To cite this version:}

Patrice Peyre, Yann Rouchausse, Denis Defauchy, Gilles Regnier. Experimental and numerical analysis of the selective laser sintering (SLS) of PA12 and PEKK semi-crystalline polymers. Journal of Materials Processing Technology, 2015, 225, pp.326-336. 10.1016/j.jmatprotec.2015.04.030 . hal01372761

\section{HAL Id: hal-01372761 \\ https://hal.science/hal-01372761}

Submitted on 5 Dec 2017

HAL is a multi-disciplinary open access archive for the deposit and dissemination of scientific research documents, whether they are published or not. The documents may come from teaching and research institutions in France or abroad, or from public or private research centers.
L'archive ouverte pluridisciplinaire HAL, est destinée au dépôt et à la diffusion de documents scientifiques de niveau recherche, publiés ou non, émanant des établissements d'enseignement et de recherche français ou étrangers, des laboratoires publics ou privés. 


\title{
Experimental and numerical analysis of the selective laser sintering (SLS) of PA12 and PEKK semi-crystalline polymers
}

\author{
Patrice Peyre*, Yann Rouchausse, Denis Defauchy, Gilles Régnier \\ PIMM, UMR 8006 CNRS-Arts et Métiers ParisTech-CNAM, 151 Bd de l'Hôpital, 75013, Paris, France
}

\begin{abstract}
A B S T R A C T
A dual experimental-numerical approach was carried out to estimate thermal cycles and resulting fusion depths obtained during the selective laser sintering (SLS) of two polymers: PA12 and PEKK. The validation of thermal cycles was obtained by considering fusion depths on single layers for different experimental conditions and temperature measurements with IR thermal camera. It was shown that a simple Beer-Lambert's heat deposit equation incorporating an extinction coefficient determined experimentally and an efficiency ratio including both laser absorption and diffusion in the powder bed were sufficient for determining accurately fusion depths, and heat cycles for the two polymers. This allowed determining optimum process conditions for manufacturing additive layers on a specifically-designed SLS set-up.
\end{abstract}

\section{Introduction}

The selective laser sintering (SLS) or selective laser melting (SLM) technique has now become a viable technique for producing parts of short series of complex shapes, not only on metals but also on polymers as shown by Kruth et al. (2007), Pham et al. (2008), or Goodridge et al. (2012). Many industrial machines already exist that allow fabricating solid thermoplastic polymer components, either on rather low fusion temperature polymers like PA6 (Pham et al., 2008) and PA12 (Dupin, 2012) polyamides, or amorphous polymers (Childs et al., 1999). Other works have focused on more technical polymers such as PEEK Schmidt et al. (2007) or PEKK (Dumoulin, 2014). When applied to semi-crystalline polymer materials, the SLS technique requires a high temperature maintain at $T_{0}$ level, comprised between the crystallization temperature start $T_{\mathrm{C}} \mathrm{s}$ and the melting temperature start $T_{\mathrm{m}} \mathrm{s}$. Too low temperatures (below $T_{\mathrm{c}} \mathrm{s}$ ) promote thermal shrinkage during crystallization and layer deformation, which is unacceptable for additive manufacturing. In turn, a small work temperature range WTR $\left(\Delta T=T_{\mathrm{m}}{ }^{\mathrm{s}}-\mathrm{T}_{\mathrm{c}} \mathrm{s}\right)$ can be a very limiting factor for a given polymer, because a precise control of the temperature becomes a critical point (Fig. 1). Crystallization rates should also be maintained at a low level during the whole process, and especially during the spreading stages, in order to limit extensive distortion that prevents stable layer addition. Other critical

\footnotetext{
* Corresponding author. Tel.: +33171936544.

E-mail address: patrice.peyre@ensam.eu (P. Peyre).
}

aspects of the SLS process come from the thermo-physical properties of polymers, especially their high viscosity (nearly $10^{6}$ times the viscosity of metals) that limits polymer flow, and resulting densification rates. However, as reminded by (Kruth et al., 2007), the reason why specific polymers such as polyamides PA sinter well compared with other polymers is not fully clear yet, even if low viscosities and molecular weights are usually considered as beneficial for enhancing powder beds densification. Although the SLS process has many industrial applications, the physical processes involved during the laser-polymer powder layer interaction are not well described because industrial set-ups do not favor physical instrumentations. Consequently, there is a real need for understanding the basic phenomena involved in the SLS process, considering more simple and opened set-ups than industrial machines. This includes the determination of laser-polymer layer coupling (absorptivity, extinction coefficients), temperature profiles $T=\mathrm{f}(t)$ on molten layers, and densification kinetics.

Previous publications have proposed macroscopic thermal numerical models for the SLM or SLS process like the 3D SLS model by Dong et al. (2009), the 3D SLM model of Hussein et al. (2013), or more microscopic models considering powder densification at a local scale like the recent work by (Defauchy, 2013). However, most of these numerical works, and especially those carried out at a macro-scale or meso-scale on commercial codes did not systematically validate their results with experimental data, and most of all did not characterize laser-powder bed interaction. Recently, Franco and Romoli (2012) have addressed laser-polymer powder interaction on single sintered lines, with the objective of analyzing 


\begin{tabular}{|c|c|}
\hline \multicolumn{2}{|c|}{ Nomenclature } \\
\hline$A$ & absorptivity \\
\hline$C_{\mathrm{p}}$ & specific heat $(\mathrm{J} / \mathrm{kg} / \mathrm{K})$ \\
\hline$D_{50}$ & average powder grain diameter $(\mu \mathrm{m})$ \\
\hline flc2hs & heaviside step function \\
\hline$f$ & PWHM laser frequency $(\mathrm{Hz})$ \\
\hline$h$ & heat convection loss coefficient $\left(\mathrm{W} / \mathrm{m}^{2} / \mathrm{K}\right)$ \\
\hline$k$ & thermal conductivity $(\mathrm{W} / \mathrm{m} / \mathrm{K})$ \\
\hline$K$ & $\begin{array}{l}\text { adjustable coefficient }(<1) \text { integrating reflectivity } \\
\text { and diffusion losses }\end{array}$ \\
\hline$P_{0}$ & mean laser power $(\mathrm{W})$ \\
\hline$P_{\text {peak }}$ & peak laser power $(\mathrm{W})$ \\
\hline$P_{\max }$ & maximum mean power $(\mathrm{W})$ \\
\hline$Q$ & surface heat flux $\left(\mathrm{W} / \mathrm{m}^{2}\right)$ \\
\hline$Q_{v}$ & volume heat flux density $\left(\mathrm{W} / \mathrm{m}^{3}\right)$ \\
\hline$r_{\text {laser }}$ & laser beam radius at $1 / \mathrm{e}^{2}(\mathrm{~m})$ \\
\hline$T_{\mathrm{m}}^{\mathrm{s}}$ & melting start temperature $(\mathrm{K})$ \\
\hline$T_{\mathrm{c}}^{\mathrm{s}}$ & crystallization start temperature (K) \\
\hline$T_{0}$ & initial temperature of the powder bed (K) \\
\hline$T_{\text {ext }}$ & $\begin{array}{l}\text { temperature of the chamber }(\mathrm{K})=\text { temperature of } \\
\text { powder layer during deposition }\end{array}$ \\
\hline$T_{\text {laser }}$ & laser period $(\mathrm{s})=1 / \mathrm{f}$ \\
\hline$t_{\mathrm{d}}$ & time for full densification of polymers (s) \\
\hline$V_{\text {spread }}$ & layer spreading speed $(\mathrm{m} / \mathrm{s})$ \\
\hline$V$ & laser scanning speed $(\mathrm{m} / \mathrm{s})$ \\
\hline$x_{\text {scale }}$ & coefficient of the heaviside step function (m) \\
\hline$\Delta H_{\mathrm{m}}$ & latent heat of melting $(\mathrm{J} / \mathrm{kg})$ \\
\hline$\alpha$ & $\begin{array}{l}\text { extinction coefficient of Beer-Lambert's equation } \\
\left(\mathrm{m}^{-1}\right)\end{array}$ \\
\hline$\Delta h$ & layer thickness (m) \\
\hline$\delta$ & porosity ratio \\
\hline$\varepsilon$ & emissivity \\
\hline$\rho$ & density $\left(\mathrm{kg} / \mathrm{m}^{3}\right)$ \\
\hline$\sigma$ & $\begin{array}{l}\text { Stefan-Boltzmann coefficient } \\
\left(=5.67 \times 10^{-8} \mathrm{~W} / \mathrm{m}^{2} / \mathrm{K}^{4}\right)\end{array}$ \\
\hline$\tau$ & laser pulse duration (s) \\
\hline
\end{tabular}

experimentally the laser energy consumption through the determination of geometrical features of fusion lines. However, they did not consider a combined numerical and experimental approach.

In another rather pioneer work by (Tolochko et al., 2000), the determination of normal spectra absorptance of a large range of

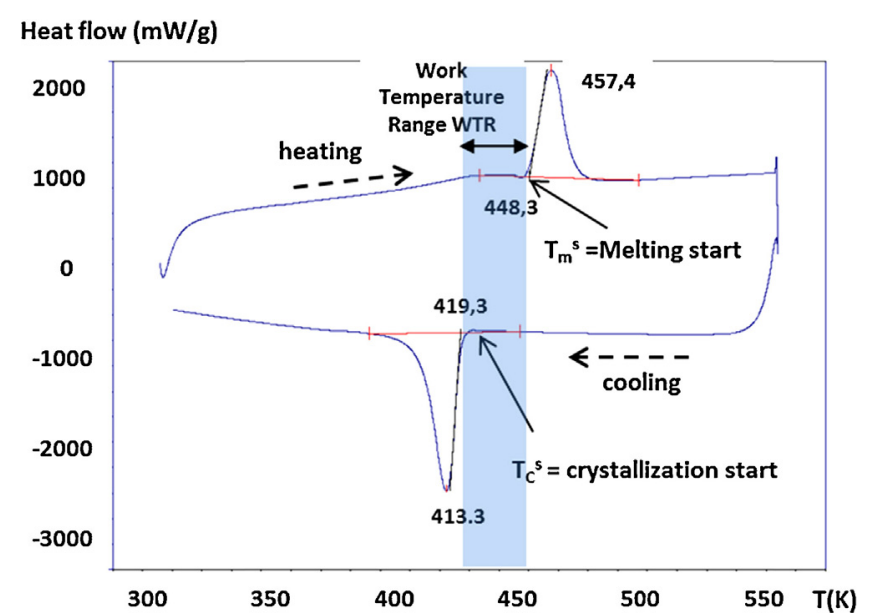

Fig. 1. DSC profile of a semi-crystalline polymer (from Defauchy, 2013)-On PA12, the rather large WTR $(\approx 29 \mathrm{~K})$ favors the SLS process. metals and polymer powders under Nd:YAG or $\mathrm{CO}_{2}$ laser irradiation was investigated, but without considering in-depth transmission aspects.

In this context the current work, carried out in the frame of a French national research project (FUI Fadiplast) was focused on three objectives: (1) to develop a small SLS prototype with dedicated diagnostics to carry out instrumented SLS tests, (2) to investigate laser-powder bed interaction, (3) to carry out numerical simulations to validate laser-material coupling and address the influence of process parameters on the thermal cycles experienced by surface layers. Two polymers have been investigated: a PA12 polyamide, and a more technical PEKK (polyetherketoneketone) with different thermo-physical properties (Table 1 ).

\section{Materials, experimental, and numerical conditions}

\subsection{The polymers}

Two semi-crystalline polymers have been investigated: a polyamide (PA12) and a PEKK, which differ mainly by their melting and crystallization temperatures (Table 1), resulting in smaller WTR for PEKK $(\approx 29 \mathrm{~K})$ than for PA12 $(\approx 17 \mathrm{~K})$, and by their viscosity $\eta$ (higher for PEKK). Moreover, the PEKK is expected to be usable at much higher temperatures (up to $570 \mathrm{~K}$ ) than the PA12 (320 K). Powder grain diameters were in-between 30 and $70 \mu \mathrm{m}$ for the PA12 polyamide and in-between 10 and $90 \mu \mathrm{m}$ for the PEKK (average value $D_{50}=50 \mu \mathrm{m}$ for both), with a more spherical shape for the PA12 powders than for the PEKK.

\subsection{The experimental SLS set-up}

A specific SLS system was fully designed and manufactured in order to investigate basic phenomena involved during the selective laser sintering of polymers. This system is composed (Figs. 2 and 3) of:

(1) Two plateaus (a manufacturing plateau, and a powder feeding plateau), with a stainless steel knife as layering device, allowing to spread layer thickness of less than $\Delta h=0.1 \mathrm{~mm}$ height with a $\pm 0.005 \mathrm{~mm}$ accuracy;

(2) Two heating systems: a resistive-heating (Joule's effect) positioned below the two plateaus, and a radiant system composed of six high power infra-red (IR) radiant lights operating in the $0.7-2 \mu \mathrm{m}$ wavelength range, and located on top of the building plateau. This heating system is different from those available in industrial machines, but allows nearly identical thermal rise and fall;

(3) A laser system composed of a $50 \mathrm{~W} \mathrm{CO}$ laser (ULR40, Continental) working in pulse width modulation mode (PWM: see Section 3.3.1) at $5 \mathrm{kHz}$ frequency at $\lambda=10.6 \mu \mathrm{m}$, a beam expander, a scanning head, and a $300 \mathrm{~mm}$ focal $\mathrm{f}$-theta lens;

(4) Different diagnostics: a pyrometer operating in the $8-14 \mu \mathrm{m}$ wavelength range, to record the temperature of the powder layer on a $5 \mathrm{~mm}$ diameter area, a SC4000 FLIR thermal camera with a $320 \times 240$ pixels sensor, working in the $2-4 \mu \mathrm{m}$ wavelength range, and a fast camera (Pixel Link) with a $200 \mathrm{~Hz}$ maximum frequency rate.

A SLS experiment can be summarized as follows: (1) a powder layer (30-80 $\mu \mathrm{m}$ thickness) is spread on the building plateau at average spreading temperatures of $373 \mathrm{~K}$ (for PA12) and 373-473 K (for PEKK), (2) after a few tens of seconds of IR heating, the powder layer surface reaches its optimum processing temperature $T_{0}$ (controlled by the pyrometer) comprised within the WTR, and the $\mathrm{CO}_{2}$ 
Table 1

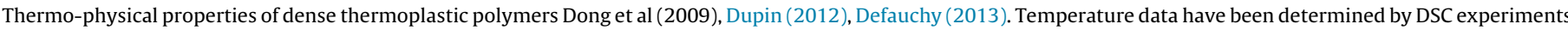
detailed in (Defauchy, 2013)

\begin{tabular}{|c|c|c|c|c|c|c|c|c|c|c|}
\hline & $T_{g}(\mathrm{~K})$ & $T_{\mathrm{m}}^{\mathrm{s}}(\mathrm{K})$ & $T_{\mathrm{c}}^{\mathrm{s}}(\mathrm{K})$ & WTR(K) & $\rho\left(\mathrm{kg} / \mathrm{m}^{3}\right)$ & $\Delta H_{\mathrm{m}}(\mathrm{J} / \mathrm{kg})$ & $C_{\mathrm{p}}(\mathrm{J} / \mathrm{kg} \mathrm{K})$ & $\eta^{*}$ (Pa s) & $\sigma(\mathrm{N} / \mathrm{m})$ & $k_{0}{ }^{*}(\mathrm{~W} / \mathrm{mK})$ \\
\hline PA12 & 325 & 448 & 419 & 29 & 1030 & 245000 & 1090 & 1100 & 0.024 & 0.23 \\
\hline PEKK & 423 & 600 & 583 & 17 & 1300 & 43000 & 1340 & 1500 & 0.032 & 0.25 \\
\hline
\end{tabular}

* Viscosity values have been identified by rheology tests carried out just above $T_{\mathrm{m}}$.

(a)

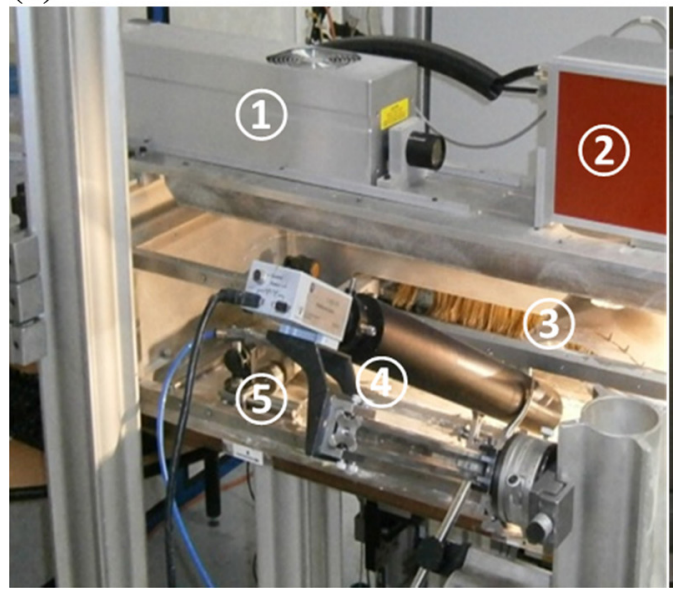

(b)

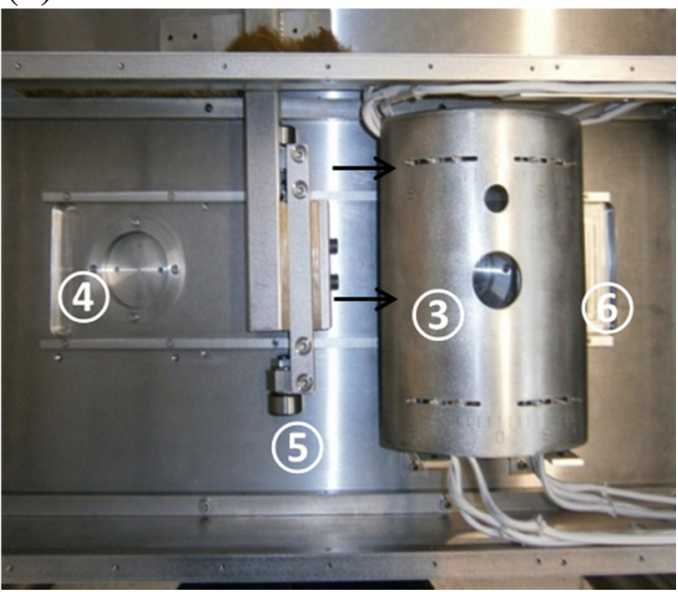

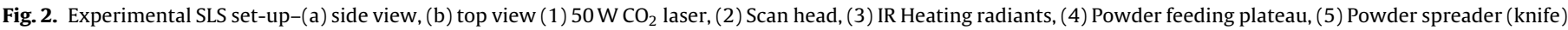
(6) Building plateau (positioned below radiants on the picture).

laser irradiates and melts a given powder thickness, (3) another layer is spread.

During all the multi-layer SLS process, the temperature of the building plateau is controlled by a PID in order to be maintained within the WTR. The experimental system and its laser marking software allow building rather simple shapes, but with rather long time durations (a few minutes) between subsequent layers. However, it allows positioning dedicated instrumentation around laser-powder interaction.

\subsection{Numerical conditions}

3D Numerical calculations of laser-heating were carried out on a laptop computer equipped with a four-core processor of $1.6 \mathrm{GHz}$ frequency and $1600 \mathrm{MHz}$ random access memory, using COMSOL
Multiphysics $^{\mathrm{TM}} 4.2$ software, and more specifically its thermal module. The meshed volume considered for the thermal simulation was a $5 \mathrm{~mm} \times 4 \mathrm{~mm} \times 1 \mathrm{~mm}$ body (Fig. 4). Linear hexahedral elements were considered, with a mesh refinement in the laser path.

The heat equation was numerically solved in transient conditions Eq. (1), with heat losses considered in terms of natural convection and radiative losses. In the equation of heat capacity Eq. (2), the energy of solid-liquid change $\Delta H_{\mathrm{m}}$ is distributed, through a Gaussian law (Bonaccina et al., 1973), between the fusion start $T_{\mathrm{ms}}$ and fusion finish $T_{\mathrm{mf}}$ temperatures $\left(\Delta T=T_{\mathrm{m}}{ }^{\mathrm{f}}-T_{\mathrm{m}} \mathrm{s}\right)$. Last, the laser heat deposit $Q_{v}$ was considered as a volume input, following a Beer's lambert attenuation law (see Section 3.1.2).

$\rho C_{\mathrm{P}}^{*} \frac{\partial T}{\partial t}=\nabla(k \nabla T)+Q_{\mathrm{V}}$

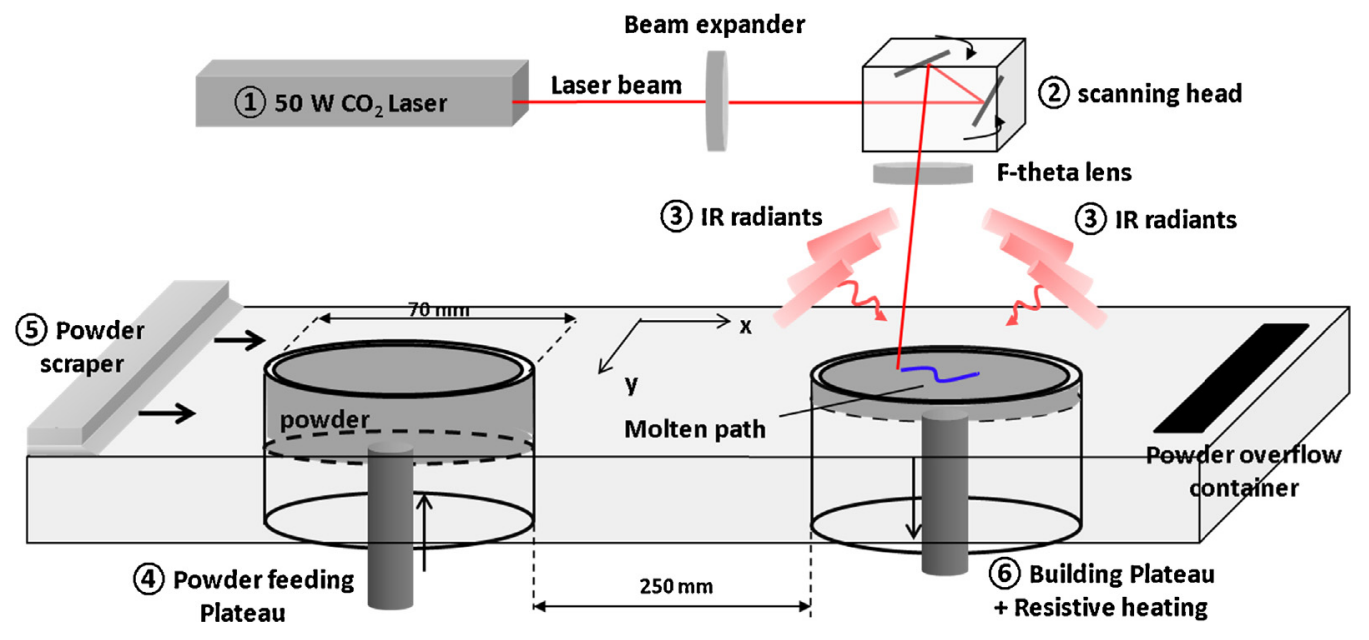

Fig. 3. Simplified scheme of the SLS device. 


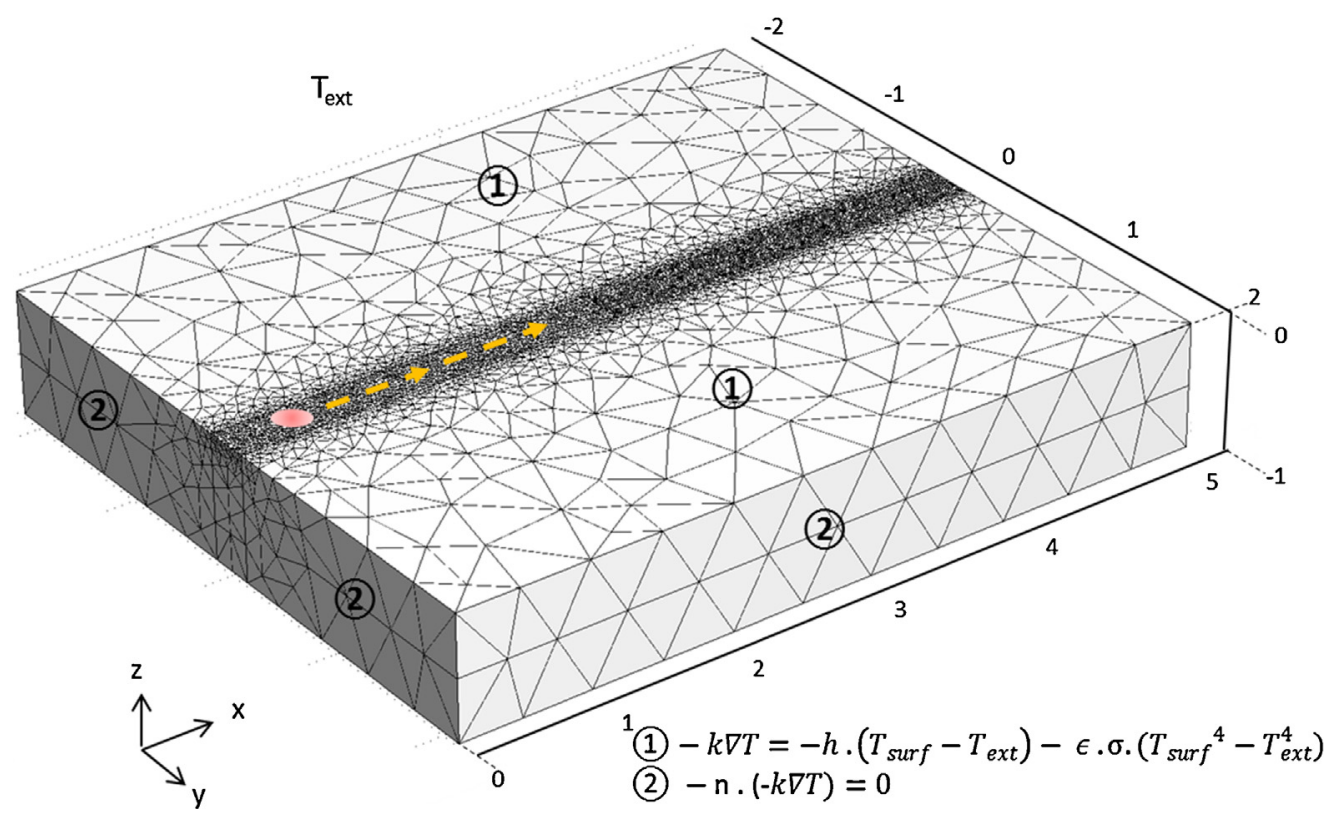

Fig. 4. 3D finite element model implemented for transient thermal calculations on COMSOL Multiphysics ${ }^{\mathrm{TM}}$.

where, $k$ is the thermal conductivity assumed to be constant with temperature, $Q_{\mathrm{v}}$ the heat source $\left(\mathrm{W} \mathrm{m}^{-3}\right)$, and $C_{\mathrm{P}}^{*}$ the modified heat capacity integrating solid-liquid phase transformation as follows:

$C_{\mathrm{p}}^{*}=C_{\mathrm{p}}(T)+\frac{\Delta H_{\mathrm{m}}}{\sqrt{\pi\left(T_{\mathrm{mf}}-T_{\mathrm{ms}}\right)^{2}}} \exp \left(-\frac{\left(T-T_{\mathrm{ms}}\right)^{2}}{\left(T_{\mathrm{mf}}-T_{\mathrm{ms}}\right)^{2}}\right)$

where, $T_{\mathrm{m}}$ is the temperature at the melting point (K), $T_{\mathrm{ms}}$ and $T_{\mathrm{mf}}(\mathrm{K})$ the temperatures of fusion start and finish respectively, $\Delta H_{\mathrm{m}}$ the enthalpy heat of fusion, $C_{\mathrm{p}}(T)=$ considered as a constant value.

The thermal conductivity $\mathrm{k}$ of the powder bed was simply taken into account by considering a porosity ratio $\delta$ as follows Dong et al. (2009):

$k=k_{0}(1-\delta)$

The tapped powder porosity ratio was estimated to be around $70 \%(\delta=0.70)$ for PA12 and 75\% $(\delta=0.75)$ for PEKK. This was evaluated considering the change of volume after melting-solidification, and the resulting displacement of the free surface.

Boundary and initial conditions were considered as follows:Initial conditions were applied as a uniform temperature distribution throughout the powder layer prior to laser melting:

$T(x, y, z, 0)=T_{0}$,

With $T_{0}=$ initial temperature of the powder bed.As boundary conditions, convective and radiative heat losses were also considered on external surfaces as follows:

$-n(k \nabla T)=-h\left(T-T_{\text {ext }}\right)-\varepsilon \sigma\left(T^{4}-T_{\text {ext }}^{4}\right)$

With $T$ is the temperature of the powder bed surface, $n=$ normal direction, $T_{\text {ext }}$ the initial ambient temperature $(373 \mathrm{~K}$ for PA12, and $473 \mathrm{~K}$ for PEKK), $h$ the natural convection coefficient at powder bed surface $=15 \mathrm{~W} \mathrm{~m}^{-2} \mathrm{~K}^{-2}, \varepsilon$ the surface emissivity assumed to be 0.8 for both powders, $\sigma=$ Stefan-Boltzmann coefficient $\left(5.67 .10^{-8} \mathrm{~W} \mathrm{~m}^{-2} \mathrm{~K}^{-2}\right)$.A continuous flux boundary condition normal to the surface $(-n(k \nabla T)=0)$ was used in the lateral and bottom part of the geometrical model to ensure a thermal continuity to the model.
As no surface deformation (volume shrinkage) was assumed in this model, the calculation of fusion zones was only carried out considering the first molten layer. It has also to be noticed that thermo-physical properties were kept unchanged after melting (no variation of $C_{\mathrm{p}}, k, \rho$ ) were considered after fusion).

\section{Results}

\subsection{Experimental analysis of the laser beam/powder coupling}

\subsubsection{Experimental determination of laser power spatial} distribution

During a SLS process, the spatial distribution of $\mathrm{CO}_{2}$ laser beam power is of rather high importance, while it directly influences local temperatures experienced by powder grains. For instance, considering similar laser power, non-uniform laser distributions, which are usual for $\mathrm{CO}_{2}$ lasers generate much higher thermal cycles $T=\mathrm{f}(t)$ at the center of laser spots, than at the near edges. To estimate the beam profile distribution, the deformation resulting from a local $\mathrm{CO}_{2}$ laser fusion induced was measured on a dense polymer. Various laser powers were used that confirmed the spatial distribution. Thanks to the measurement with a 2D profilometer of the shape of the resulting fused crater (case of a static $27.5 \mathrm{~W}-\mathrm{CO}_{2}$ laser irradiation in Fig. 5), an analytical function could be proposed for the focused beam profile. The spatial distribution is shown to be nearGaussian in shape (with a laser radius $r_{\text {laser }}$ equal to $120 \mu \mathrm{m}$ ), and the analytical function providing the best fitting with experimental measurement becomes:

$Q_{0}=K n \frac{P_{0}}{\left(\pi r_{\text {laser }}^{2}\right)} \exp \left(-n \frac{\left(x^{2}+y^{2}\right)}{r_{\text {laser }}^{2}}\right)$

where, $Q_{0}=$ surface heat flux $\left(\mathrm{W} / \mathrm{m}^{2}\right), n=4, r_{\text {laser }}(\mathrm{m})=$ laser radius at $1 / \mathrm{e}^{2}=120 \mu \mathrm{m}, P_{0}(\mathrm{~W})=$ average laser power, $K=$ adjustable coefficient $<1$ integrating reflectivity $R$ and Mie diffusion $D$ factors $(K=(1-R)(1-D))$ of the laser through the powder layer.

\subsubsection{Laser power transmission measurements}

Once laser beam distribution was characterized, it became important to investigate laser transmission through the powder 


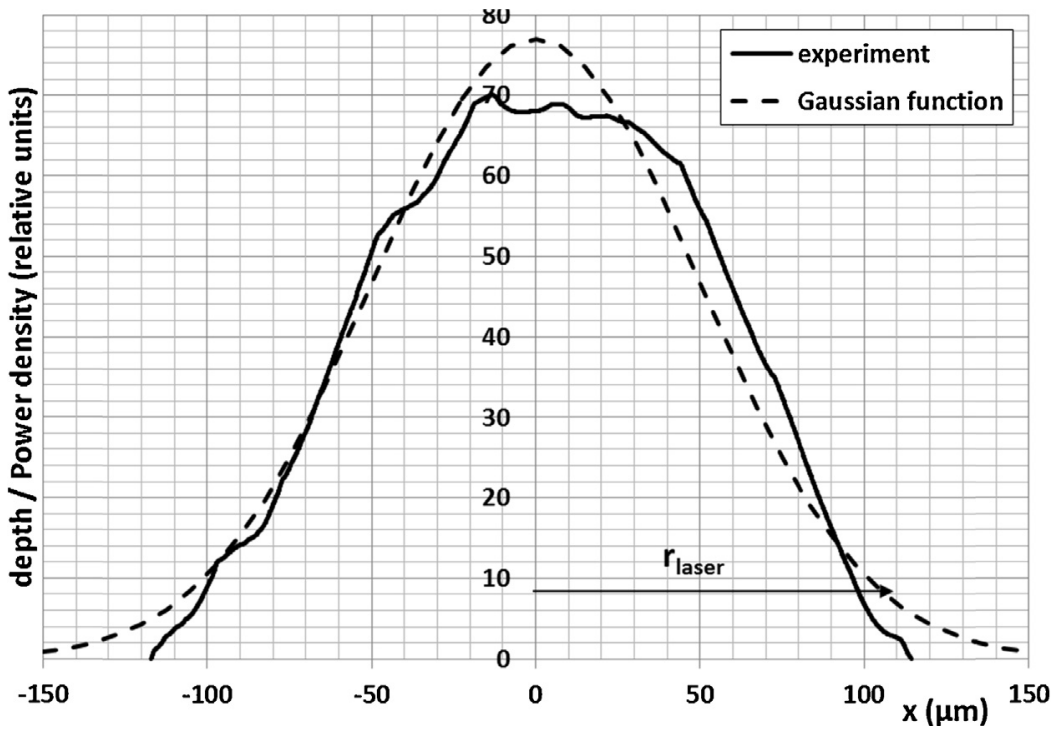

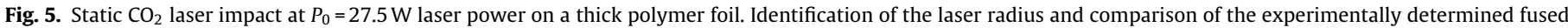
profile (2D profilometer) with an analytical quasi-Gaussian distribution.

layers to be able to estimate a reliable analytical heat input for numerical calculations.

For this purpose, a specific device was developed, allowing measurement of the transmission of various powder layer thicknesses, in order to determine the power versus depth attenuation law. The experimental set-up is shown in Fig. 6a. The tapped powder layers, with various thickness obtained using thin foils in the lateral part of the set-up, were spread on a $5 \mathrm{~mm}$-thick $\mathrm{NaCl}$ window, allowing a $95 \%$ transmission of the $\mathrm{CO}_{2}$ laser beam. Assuming that no transmission difference exists between ambient and pre-heated powder bed, such measurements were useful data for numerical calculations. Results (Fig. 6b) indicate a fast in-depth attenuation of the transmitted laser beam. This attenuation (and in-turn the laser absorption-diffusion in the powder layer) is shown to follow a Beer-Lambert's equation Eq. (7), which is even more pronounced for the PA12 than for the PEKK. This results in a higher extinction coefficient $\alpha$ for PA12 $\left(9000 \mathrm{~m}^{-1}\right)$ than for PEKK $\left(7500 \mathrm{~m}^{-1}\right)$.

$Q(z)=Q_{0} \exp (-\alpha z)$

where, $\alpha$ is the extinction coefficient and $Q_{0}(\mathrm{x}, \mathrm{y})$ the surface heat deposit $\left(\mathrm{W} / \mathrm{m}^{2}\right)$

\subsection{Experimental determination of fusion depths}

SLS tests were carried out on single layers to determine the evolution of molten depths with experimental parameters. Scanning speeds $V$ in the $0.1 \mathrm{~m} / \mathrm{s}-1 \mathrm{~m} / \mathrm{s}$ range were considered, together with laser power $P_{0}$ in-between $1.7 \mathrm{~W}$ and $7 \mathrm{~W}$ for both PA12 and PEKK powder layers.

Prior to laser-melting tests, powder layers ( $5 \mathrm{~mm}$ thick to limit thermal gradients) were pre-heated up to a $T_{0}$ temperature $(440 \mathrm{~K}$ on PA12, and $600 \mathrm{~K}$ on PEKK) by using thermal resistances and IR radiant light sources $(0.75-2 \mu \mathrm{m})$. The surface temperature was controlled by an IR pyrometer, and regulated by a PID system, that allows limiting local thermal variations to less than $\pm 2 \mathrm{~K}$. The thermal gradient on the building plateau was near $10 \mathrm{~K}$ between the edges and the center of the powder bed.

For each condition, optical microscopy was used to estimate fusion depths $h$ (Fig. 7), without taking into account non-melted agglomerated particles. The variation of molten depths was shown to follow a linear dependence versus $P_{0} / V^{0.5}$ on the two powders investigated so far (Fig. 8).

\subsection{Numerical simulation of the SLS process}

The numerical description of SLS was considered through the following three aspects:

- The analysis of the PWM regime in order to check the ability of a numerical continuous heat deposit to reproduce a pulsed laser irradiation;

- The FE calculation of fusion depths and thermal cycles induced by SLS;

- The influence of layer deposition on thermal stability of the powder bed.

\subsubsection{Numerical analysis of the pulse width modulation (PWM)} regime

The $\mathrm{CO}_{2}$ laser used for SLS experiments operates in pulsed regime at $f=5 \mathrm{kHz}$ maximum frequency (period $T_{\text {laser }}=0.2 \mathrm{~ms}$ ) and delivers a peak power of $P_{\text {peak }}=50 \mathrm{~W}$. Like most of the $\mathrm{CO}_{2}$ lasers for SLS applications, it adjusts the mean output power $P_{0}$ by multiplying a constant output peak power value $P_{\text {peak }}$ by a duty cycle value $\mathrm{dc}=\tau f$ (with $\tau=$ laser pulse duration, $f=$ pulse frequency) Eq. (8). For instance, a $10 \% \mathrm{dc}$ is required to obtain a $P_{0}=P_{\text {peak }}$. $\mathrm{dc}=5 \mathrm{~W}$ value, starting from a $50 \mathrm{~W}$ peak power (Fig. $9 \mathrm{a}$ ). This configuration is known as pulse width modulation (PWM) mode.

In PWM regime, low dc values can promote discontinuous laser melting when the scan speed is higher than a scan speed threshold $V_{\text {max }}$. This $V_{\text {max }}$, which enables an overlap between laser spots (Fig. 9b), was calculated by Eq. (9). Considering an average power $P_{0}=5 \mathrm{~W}$ and a laser radius $r_{\text {laser }}=125 \mu \mathrm{m}$, a $V_{\text {max }}=1.56 \mathrm{~m} / \mathrm{s}$ was found. Above $V_{\max }$, laser impacts do not intersect at all.

$P_{0}=P_{\text {peak }} \frac{\tau}{T}=P_{\text {peak }} \tau f$

$V_{\text {max }}=\frac{2 r_{\text {laser }}}{\left(T_{\text {laser }}-\tau\right)}=\frac{f P_{\text {peak }} 2 r_{\text {laser }}}{P_{\text {peak }}-P_{0}}$

FE simulations of the SLS process reported in the literature Dong et al. (2009) usually consider a continuous laser irradiation, even if lasers operate in a PWM regime.

To further investigate this aspect, and determine the range of applicability of the cw assumption, 2D simulations were carried out to calculate thermal cycles $T=\mathrm{f}(t)$ induced by either a pulsed laser 

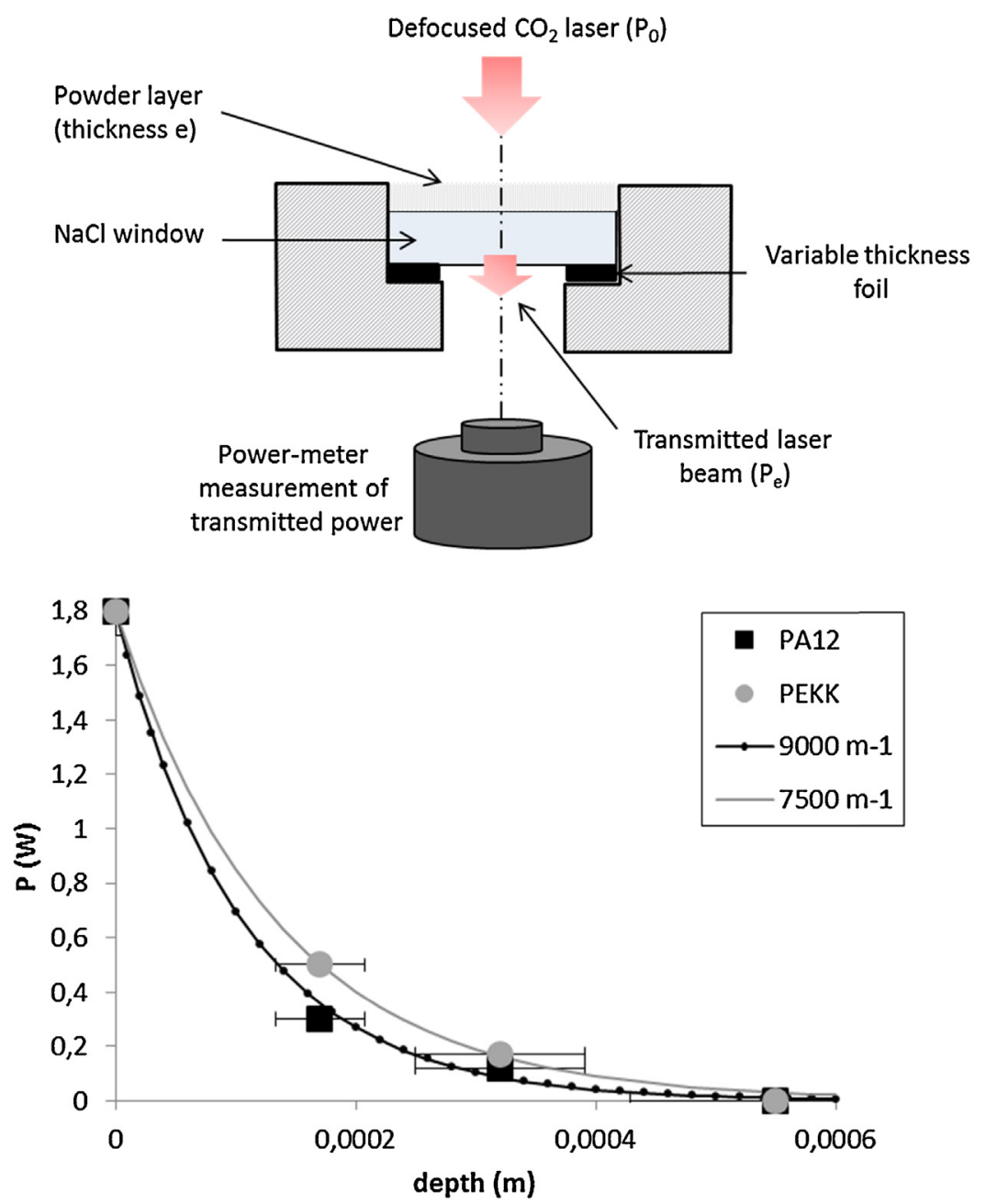

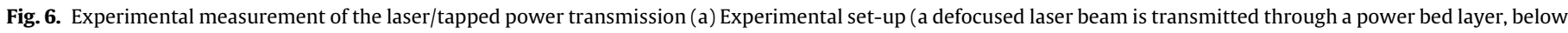
which a power measurement is carried out), (b) results obtained on PA12 and PEKK powders for a $1.8 \mathrm{~W}$ incident power.

mode $\left(P_{\text {peak }}, \tau_{\text {laser }} f\right)$ or the corresponding cw regime $\left(P_{0}=P_{\text {peak }} \tau f\right)$. The pulsed regime was simulated by considering rectangular laser pulses of $\tau_{\text {laser }}$ duration. Numerical results (Fig. 10) confirm that for $V<<V_{\max }$, the temperature profile, and especially the maximum temperature induced by the real pulsed mode and the equivalent $\mathrm{cw}$ regime are nearly the same (maximum variation $= \pm 10 \mathrm{~K}$ ), whatever the position considered. Considering laser radii $r_{\text {laser }}$ equal to $120 \mu \mathrm{m}$ and frequencies equal to $5 \mathrm{kHz}$, a fully continuous laser melting was only obtained for $\mathrm{V}<0.5 V_{\max }$ corresponding to an inter-spot distance near $r_{\text {laser }}$ (Fig. 9b). Above this value $(=0.78 \mathrm{~m} / \mathrm{s})$, more pronounced thermal variations occur (up to $\Delta T=50 \mathrm{~K}$ ), the surface melting becomes heterogeneous, and a cw irradiation cannot be considered anymore for the simulations. Consequently, experimental conditions have been restricted to scanning speeds below $V=0.78 \mathrm{~m} / \mathrm{s}$.

In Fig. 10, the calculated time maintain above $T_{0}(=520 \mathrm{~K})$ is approximately $0.1 \mathrm{~s}$, which is far from providing a full densification of polymers. Indeed, according to (Frenkel, 1945) the time for densification of polymers $t_{\mathrm{d}}$ can be estimated by Eq. (10) where, $\eta=$ dynamic viscosity (Pa s), $D_{50}=$ average grain size (m), $\sigma=$ surface tension $\left(=0.003 \mathrm{~N} \mathrm{~m}^{-1}\right.$ on the two polymers). This makes $t_{\mathrm{d}}=18 \mathrm{~s}$ on PA12 and $t_{\mathrm{d}}=25 \mathrm{~s}$ for PEKK, with physical data from Table 1. (a)

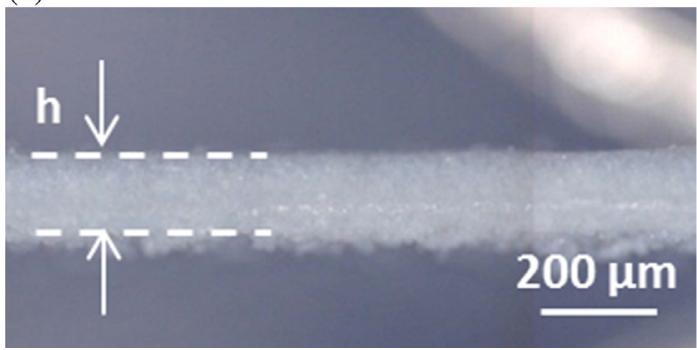

(b)

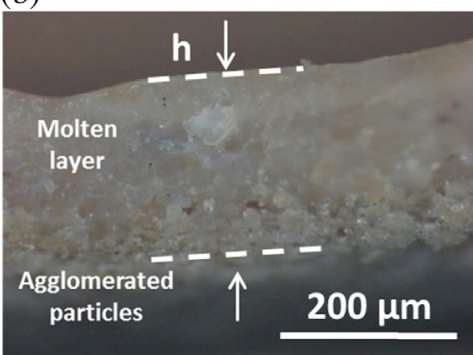

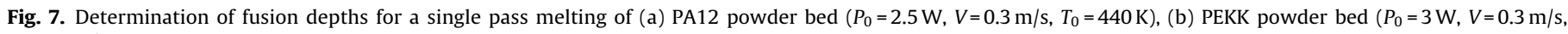
$\left.T_{0}=600 \mathrm{~K}\right)$. 


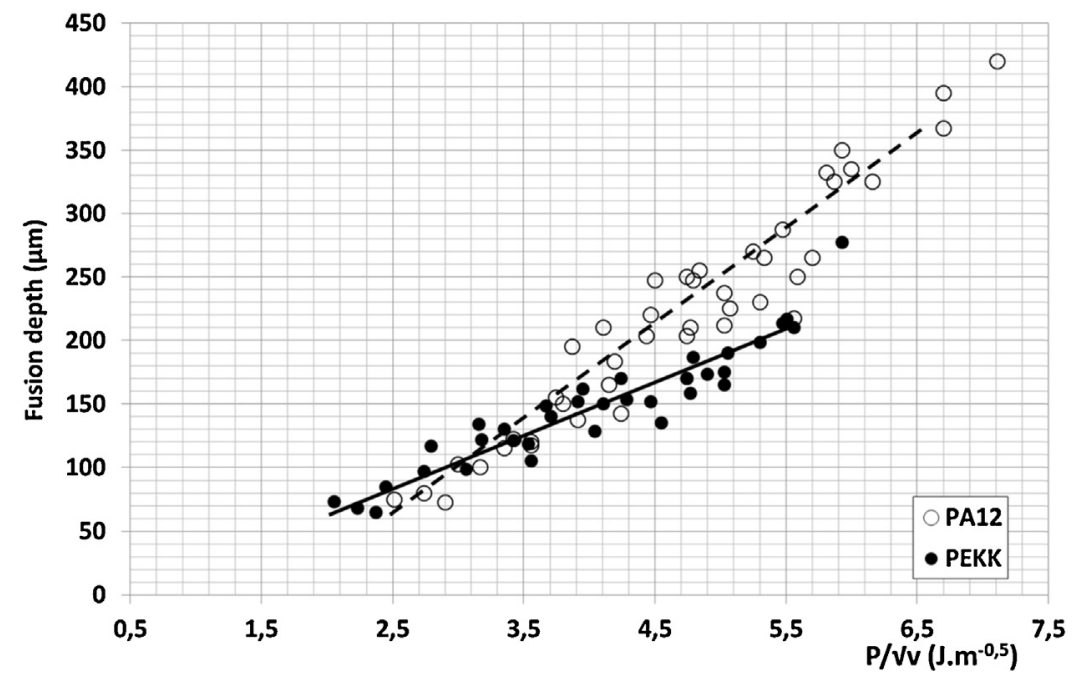

Fig. 8. Variation of experimental molten depth with the laser process parameter $P_{0} / V^{0.5}$ (Preheating temperatures $T_{0}$ PA12 $=440 \mathrm{~K}$ and $T_{0}$ PEKK $=600 \mathrm{~K}$ ).

(a)

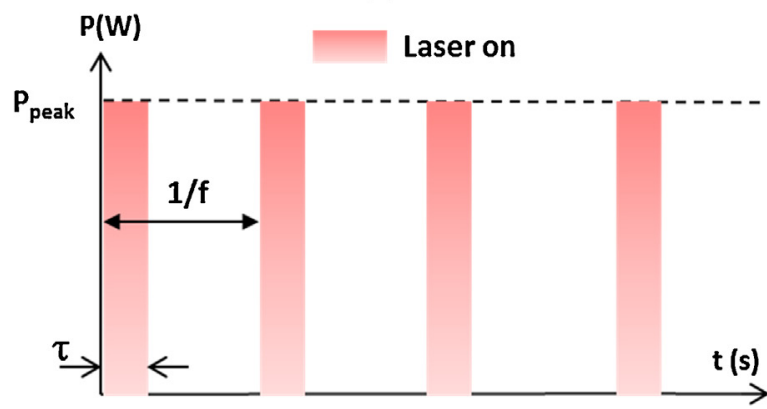

(b)

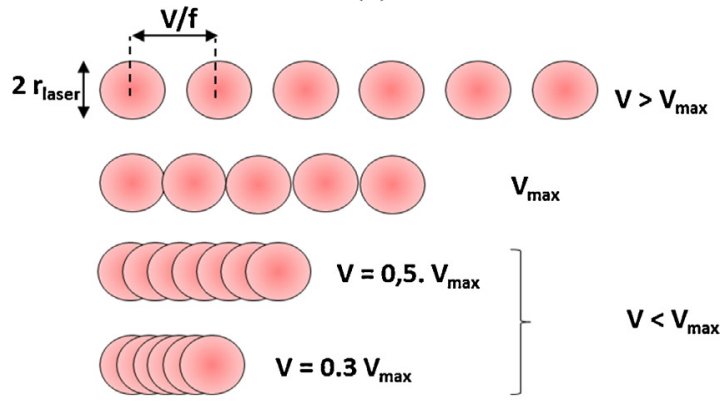

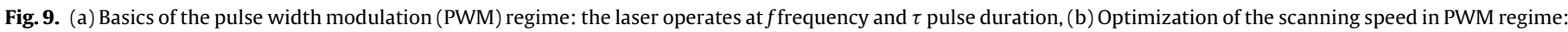
for scanning speeds above $0.5 V_{\max }$, a discontinuous SLS is obtained.

Such large densification times justify afterwards why SLS machines operate at a temperature level above the crystallization temperature, and maintain this temperature a long time after the laser switch-off.

$t_{\mathrm{d}}=\frac{\eta D_{50}}{\sigma}$

\subsubsection{Numerical calculation of single fusion lines}

In a second step, numerical calculations of fusion depths were carried out for the two polymer powders. As extinction coefficient $\alpha\left(\mathrm{m}^{-1}\right)$ and spatial distribution $P=\mathrm{f}(\mathrm{x}, \mathrm{y})$ have been experimentally determined (Section 3.1), the only adjustable factor is the $K$ value Eq. (7), which corrects heat input by considering reflectivity and Mie diffusion losses through the powder bed.
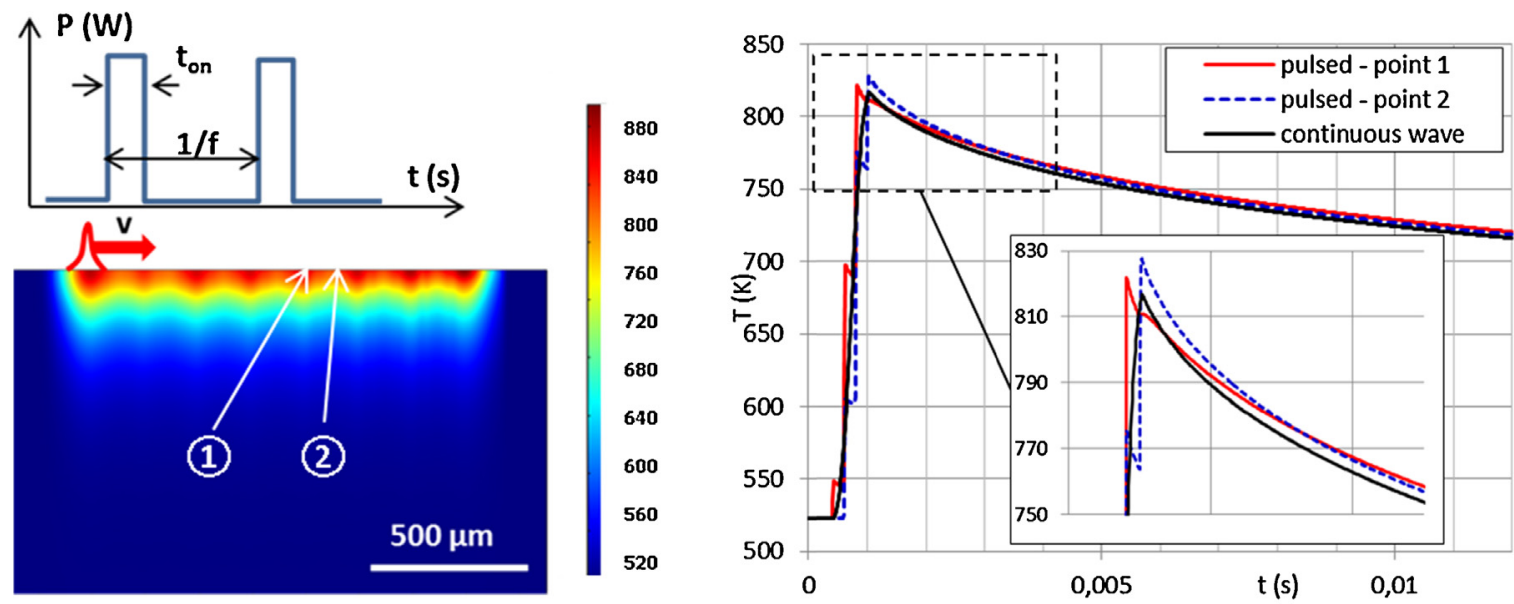

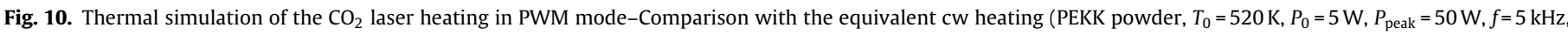
$V=0.5 \mathrm{~m} / \mathrm{s}$ ) 
(a)

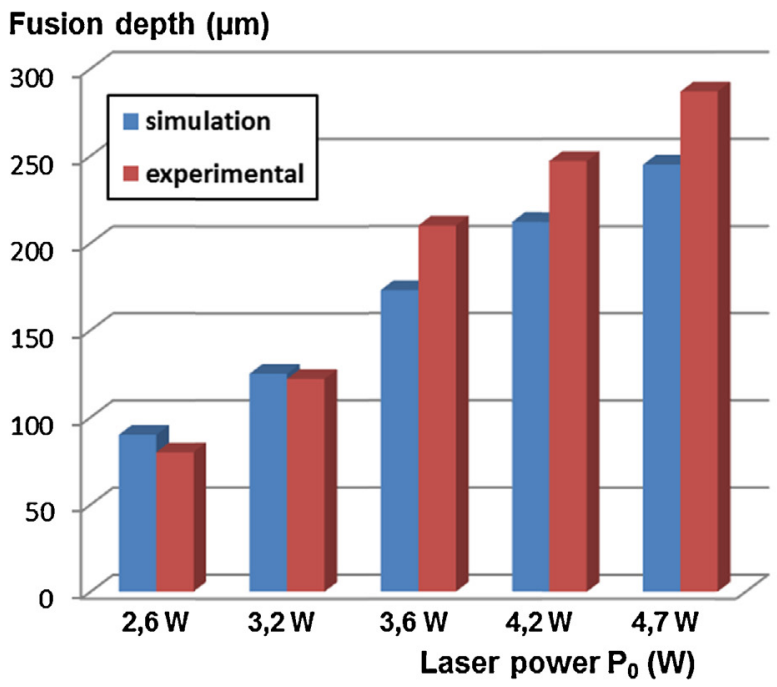

(b)

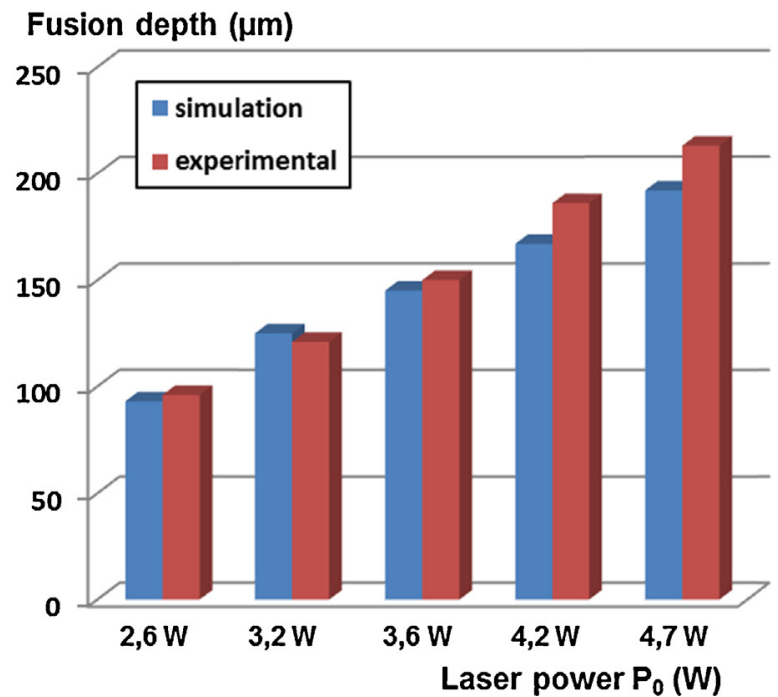

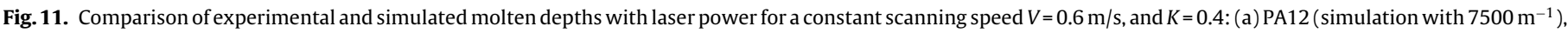
(b) PEKK (simulation with $\alpha=7500 \mathrm{~m}^{-1}$ ).

The numerical model was shown to reproduce correctly fusion depths on PEKK layers with the use of a $K=0.4$ factor (Fig. 11), which indicate afterwards that approximately $60 \%$ of the incident power is lost by reflection or diffusion processes, whereas only $40 \%$ contributes to the polymer melting.

However, on PA12 fusion lines, the experimental $\alpha$ value $\left(9000 \mathrm{~m}^{-1}\right)$ was shown to underestimate the real variation of fusion depths. For this reason, alpha was slightly decreased down to $7500 \mathrm{~m}^{-1}$, which is coincidently the same value than for PEKK, in order to provide a better fitting with experiments. Consequently, similar $\mathrm{K}$ and alpha coefficients were numerically identified on PA12 or PEKK polymer layers.

This allowed us estimating numerically the maximum temperatures carried out during the SLS process (Fig. 12). For instance, for a $0.6 \mathrm{~m} / \mathrm{s}$ scanning speed (Fig. 12), maximum calculated temperatures, averaged on a $0.1 \mathrm{~mm}$ diameter around the laser, were comprised between $690 \mathrm{~K}$ and $875 \mathrm{~K}$ for increasing laser powers.

Even if the cooling part of $T=\mathrm{f}(t)$ curves could be correctly reproduced (Fig. 13), the comparison of simulated and experimental $T=\mathrm{f}(t)$ thermal profiles was not very successful. Simulations indicate a $740 \mathrm{~K}$ maximum temperature, whereas the thermal

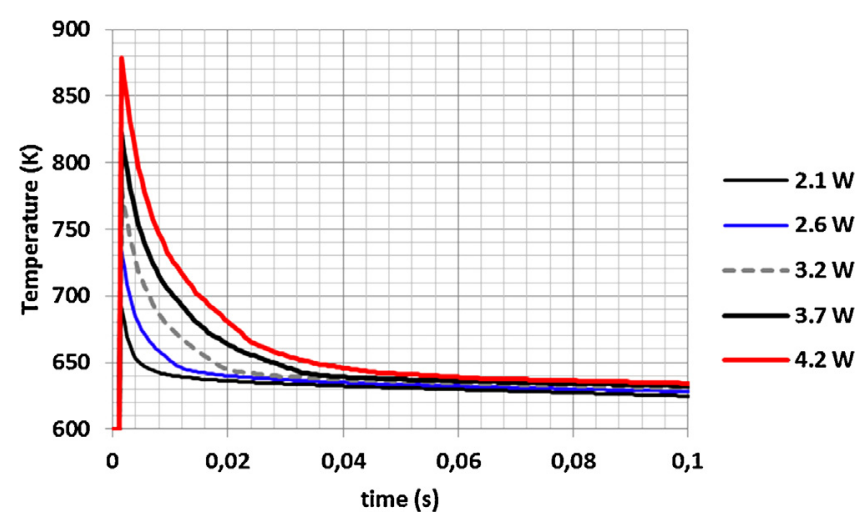

Fig. 12. Influence of laser power $P_{0}$ on the thermal cycles $T=\mathrm{f}(t)$ calculated at the surface of the powder bed (PEKK powder, $V=0.6 \mathrm{~m} / \mathrm{s}$, pre-heating up to $600 \mathrm{~K}$ ). Maximum temperatures vary between $690 \mathrm{~K}$ and $875 \mathrm{~K}$. measurement indicated maximum temperatures near $635 \mathrm{~K}$. Two explanations are possible: (1) the lack of spatial resolution of the thermal camera sensor $(1$ pixel $=180 \mu \mathrm{m} \times 180 \mu \mathrm{m})$ which averaged thermal measurements in the laser-powder bed interaction zone, and lowers maximum determined temperatures, (2) a change of emissivity of PEKK above $T_{\mathrm{m}}$ (with a $\varepsilon$ decrease), which would minimize the apparent temperature.

On a given powder bed, numerical simulations indicate a quasilinear variation of surface temperatures with $P_{0}$ (Fig. 14). By comparing calculated temperatures, with the surface morphology and the color of the powder bed, temperature thresholds assumed to provoke the thermal degradation (thermo-oxidation) of the polymer were determined. Above $760 \mathrm{~K}$, the first deterioration traces (black spots) are visible on the PEKK surface, and above $825 \mathrm{~K}$, most of the polymer surface is degraded. Such modifications of the polymer surface are mostly due to the limited gas shielding used in the process (the $\mathrm{O}_{2}$ content was lowered to near $5 \%$ due to Argon flow, but was somewhat superior to $\mathrm{O}_{2}$ levels in industrial machines). However, the model is assumed to allow predicting correctly degradation thresholds.

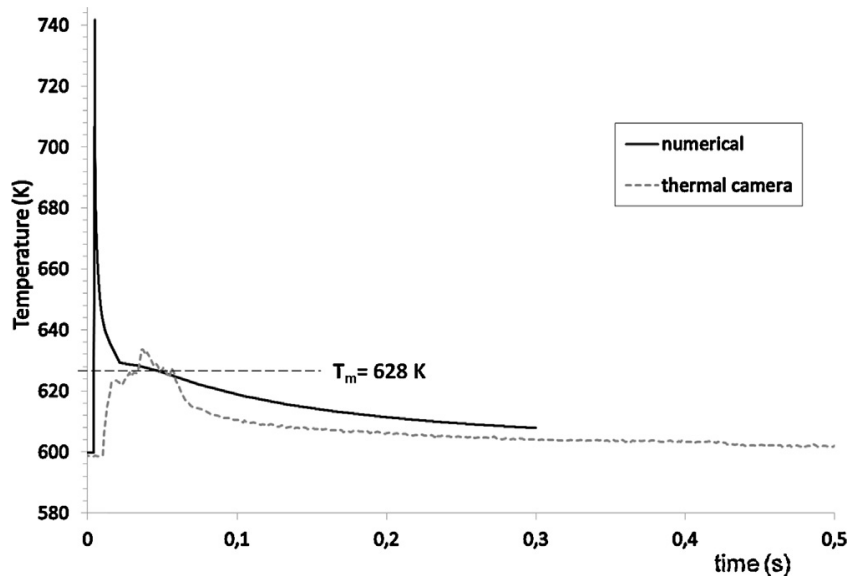

Fig. 13. Comparison of experimental and simulated thermal profile (PEKK powder, $\left.V=0.6 \mathrm{~m} / \mathrm{s}, T_{0}=600 \mathrm{~K}, P_{0}=2.6 \mathrm{~W}\right)$. 

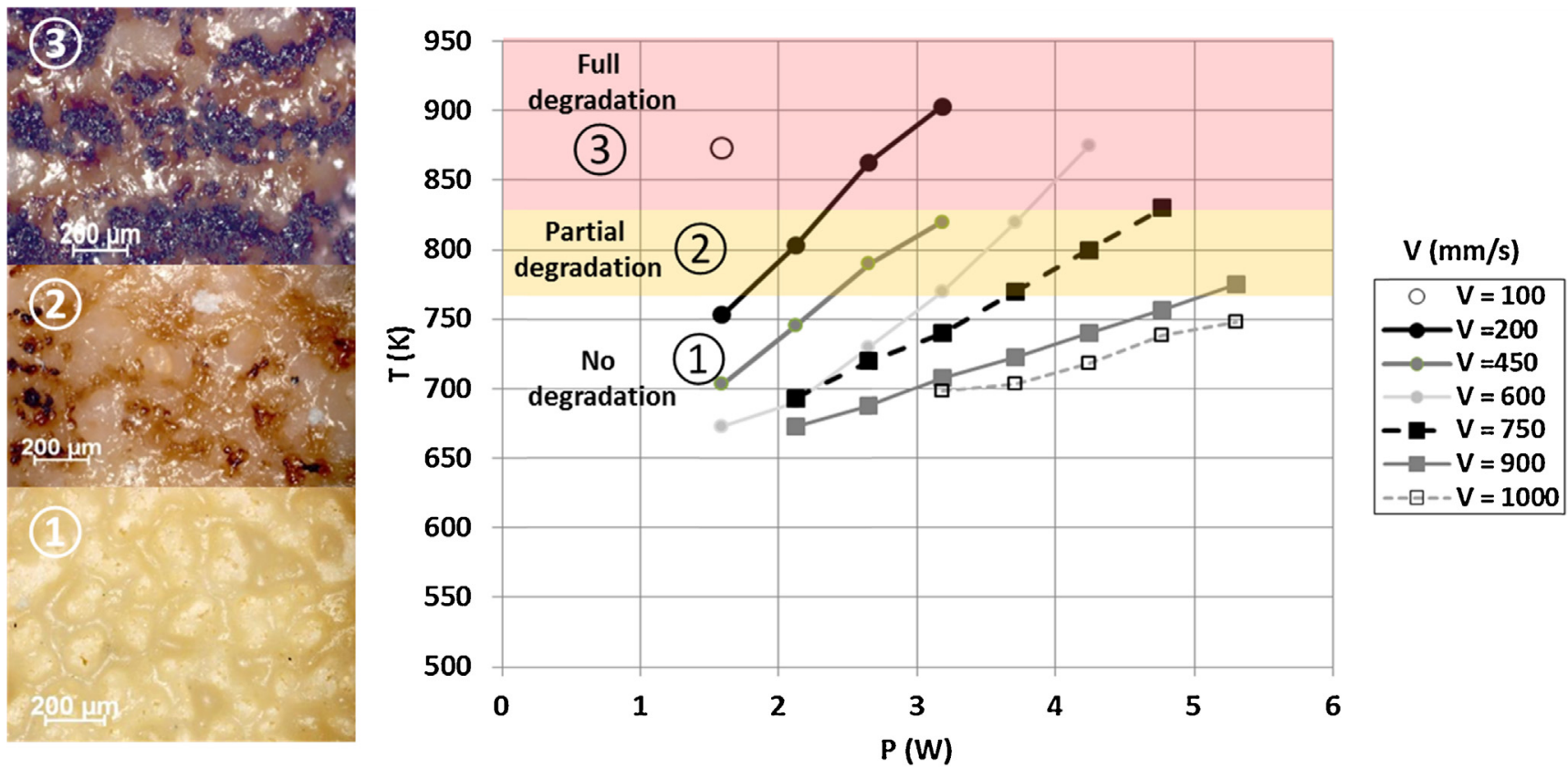

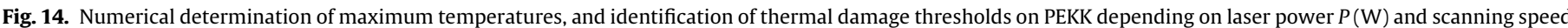

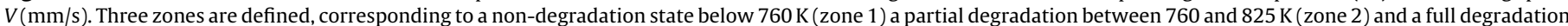
above $825 \mathrm{~K}$ (zone 3).

\subsubsection{Influence of layer deposition conditions on powder bed temperature}

One of the main technical issues of SLS is to maintain stable temperature levels during the SLS process in order to: (1) limit thermally induced deformations and stresses (dependent on thermal gradients $G(K / m)$ ) and (2) favor densification Eq. (10). Such deformations are particularly important during crystallization i.e., when the local temperature becomes lower than the crystallization temperature $T_{\mathrm{c}}$.

Excessive cooling rates are susceptible to occur during layer deposition, because of the lower temperature of the spread powder layer which induces a thermal sinking effect.

A specific numerical approach has been proposed to estimate optimum layer deposition conditions (thickness of deposited powder layer $\Delta h_{\text {powder }}$, temperature of the deposited powder $T_{\text {powder }}$, deposition speed $V_{\mathrm{d}}$ ) allowing maintaining the temperature of powder beds above $T_{\mathrm{c}}$.

Basically, the numerical model uses a time-dependent Heaviside Step function flc2hs included in COMSOL Multiphysics ${ }^{\mathrm{TM}}$ a time variation $\kappa(\mathrm{x}, \mathrm{y}, \mathrm{z}, \mathrm{t})$ of thermal conductivity Eq. (11) to simulate the layer deposition sequence, as already used by Peyre et al. (2008) for the DMD process. This function simulates a continuous transition from a $k=0 \mathrm{~W} / \mathrm{mK}$ state (the air) at $T_{\text {ext }}$ temperature $=$ (the temperature of the chamber) to a $\mathrm{k}(T)$ state (the deposited powder bed). With such an approach, it becomes possible to estimate the local time-temperature cycle $T=f(t)$ of the powder bed surface during layer deposition, and to evaluate the influence of various deposition parameters on fused powder thermal stability.

$\kappa(T, t, x, z)=k(T)\left(1-\operatorname{flc} 2 \mathrm{hs}\left(x-x_{0}-V t, x_{\text {scale }}\right)\right)$

where, flc2hs $=$ Heaviside step function, $x_{\text {scale }}=$ transition interval, $x_{0}=$ initial positions, $V=$ scanning speed $(\mathrm{m} / \mathrm{s})$

In Fig. 15, the influence of powder layer thickness on surface temperature is reported, considering a powder layer deposited at $373 \mathrm{~K}$ on a pre-fused powder bed with a $610 \mathrm{~K}$ stabilized temperature following laser surface melting (Fig. 12). A rather low effect is shown on minimal temperatures $(5 \mathrm{~K})$, indicating that sinking effects are only a little dependent on powder layers thickness. For this specific configuration, the minimum temperature reached on the molten layer is $565 \mathrm{~K}$, which level is expected to be below the crystallization start on PEKK.

Considering similar calculations, a processing map for powder deposition conditions (Fig. 15b) was established, allowing the selection of optimum process parameters. This map includes factors such as: the temperature of deposition $\left(=T_{\text {ext }}\right)$, the temperature of the molten powder bed surface $T_{\text {surf }}$ before spreading and the powder layer thickness. As shown in Fig. 15a, this last factor has almost no effect on thermal-microstructural transitions. Similarly, the spreading speed $V_{\text {spread }}$ (considered between $0.5 \mathrm{~mm} / \mathrm{s}$ and $10 \mathrm{~mm} / \mathrm{s}$ ) did not have significant influence on the processing map. Transitions were considered according to the crystallization peak of PEKK (crystallization start at $590 \mathrm{~K}$, crystallization peak at $580 \mathrm{~K}$, crystallization ends at $570 \mathrm{~K}$ ). Consequently, with the use of such a processing map, one can select optimum powder spreading conditions. For instance, for an external temperature $\mathrm{T}_{\text {ext }}(\approx$ powder layer temperature) of $480 \mathrm{~K}$, the temperature of the molten powder bed before deposition should be superior to $605 \mathrm{~K}$ to fully avoid crystallization. On the other hand, considering a surface temperature before deposition of $590 \mathrm{~K}$, a full crystallization will necessarily occur for $T_{\text {ext }}<440 \mathrm{~K}$.

\subsection{Selective laser sintering of additive polymer layers}

Examples of multi-layers PA12 samples are shown in Fig. 16, for various process conditions applied on five additive layers of simple squared geometries. For low $P / V^{0.5}$ ratios, incomplete melting occurs (right sample from Fig. 16), whereas excessive $P / V^{0.5}$ values provide thermal distortions (left sample on Fig. 16). Finally, optimum process conditions were found $(0.2 \mathrm{~m} / \mathrm{s}, 1.6 \mathrm{~W})$ where the density, estimated by a double weighing technique (Dumoulin, 2014), was shown to be approximately $95 \%$, which is rather satisfactory. However, overheating effects at the edge of the samples were evidenced, which have been attributed to a slowing down of the scanning head at the beginning and the end of each fusion lines. This caused a thermally induced curvature of the samples (Fig. 17), despite a pyrometer control of the surface temperature of the 
(a)

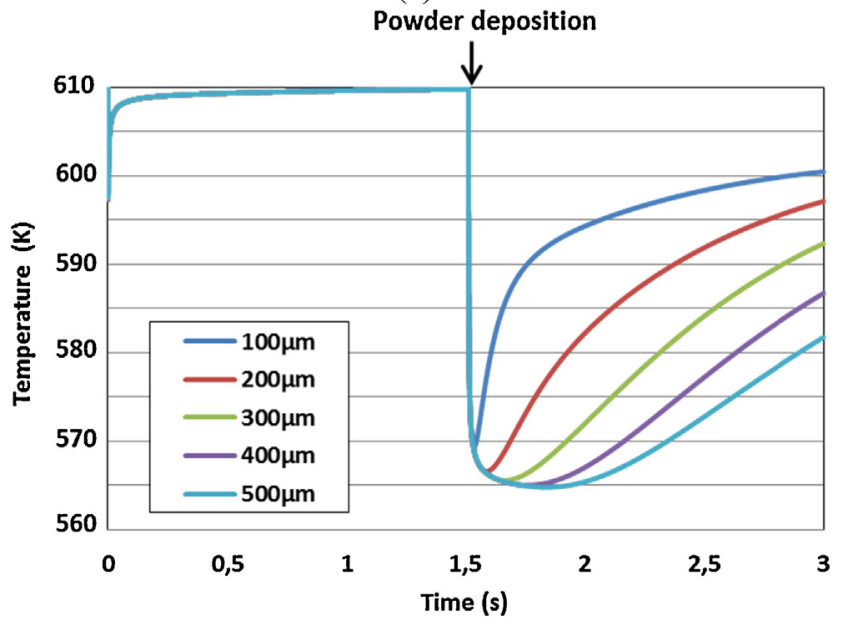

(b)

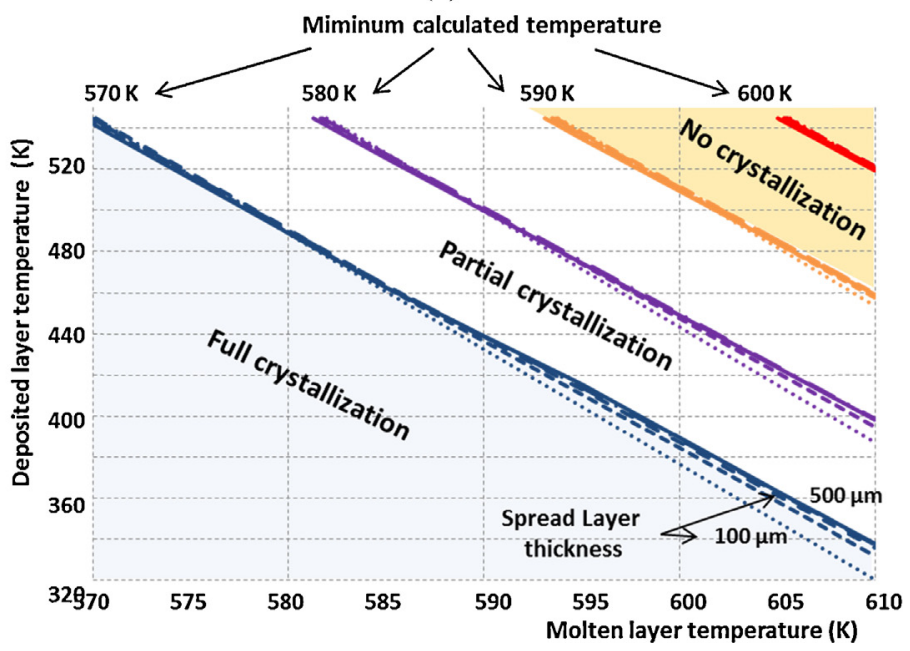

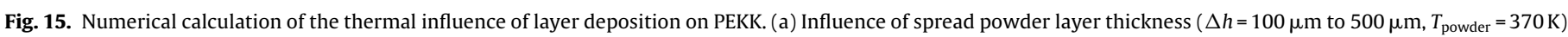
on fused powder cooling rates (molten layer temperature $=610 \mathrm{~K}$ ), (b) numerical processing map considering the temperatures of spread layers ( $\mathrm{y}$ ) and molten layer $(\mathrm{x}$ ).

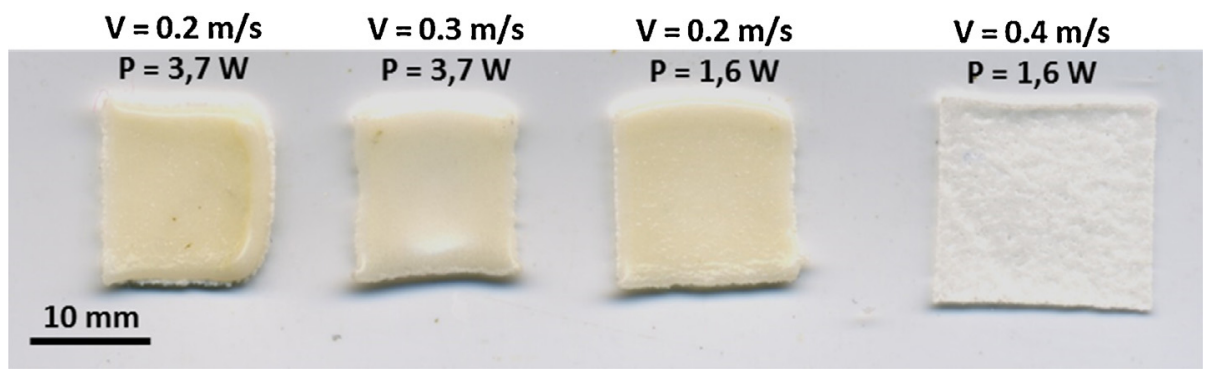

Fig. 16. SLS Fabrication of squared PA12 samples obtained with various process conditions $\left(T_{0}=440 \mathrm{~K}\right.$, five layers $)$.

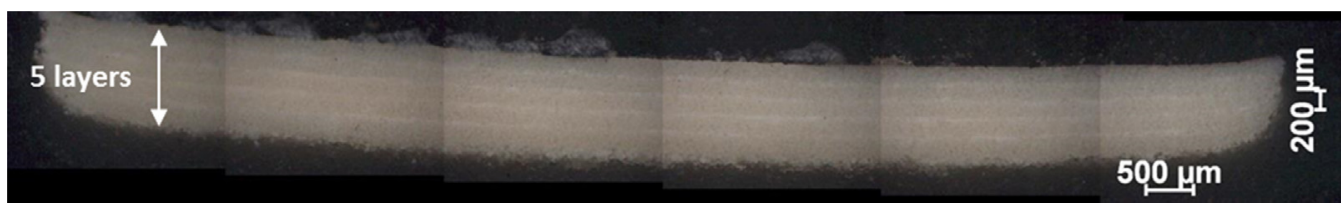

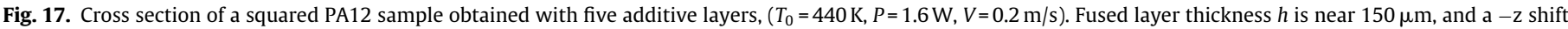
of $-120 \mu \mathrm{m}$ of the building plateau has been used to carry out additive layers.

powder bed, which was stabilized to $T_{0}=440 \mathrm{~K} \pm 5 \mathrm{~K}$ during the whole process.

On PEKK powder beds, thermal distortions were even more pronounced on PEKK samples than on PA12 specimens, for similar $P / V^{0.5}$ ratios (Fig. 18, Fig. 19). Some degradations were also confirmed for similar $\left(P_{0}, V\right)$ thresholds than those determined on single fusion lines (Fig. 14). However, optimum porosity rates were shown to be near $15 \%$ on PEKK, especially due to a lack of re-melting of interlayer zones. The reason why porosity rate could not be reduced was attributed to the geometrical deformation of the samples during the SLS process that necessitated increasing $-z$ shift values between each layer to avoid contact between the

\section{$0.8 \mathrm{~m} / \mathrm{s}$}
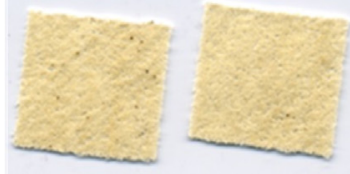

$10 \mathrm{~mm}$
$0.6 \mathrm{~m} / \mathrm{s}$

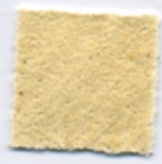

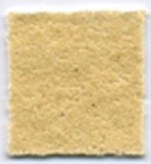

$0.4 \mathrm{~m} / \mathrm{s}$

$0.2 \mathrm{~m} / \mathrm{s}$
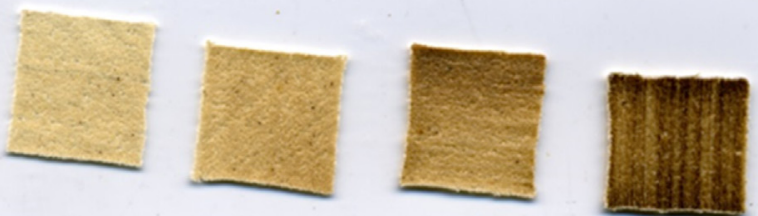

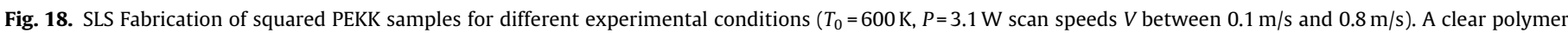
degradation is evidenced below $0.3 \mathrm{~m} / \mathrm{s}$ scan speed. 


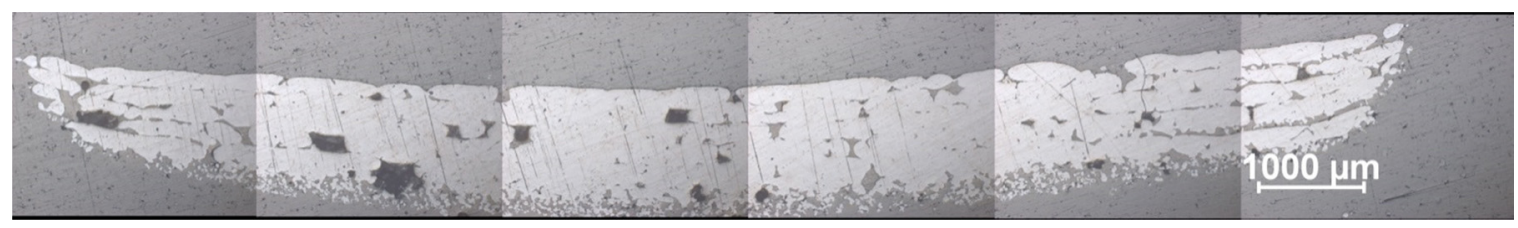

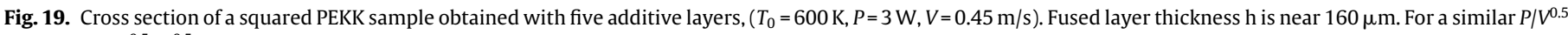

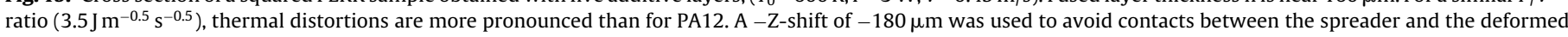
polymer.

powder scraper and the fused sample. Such extended deformations were due to the combined effect of: (1) the limited work temperature range for PEKK that makes difficult avoiding crystallization, (2) overheating effects near the samples edges due to non-constant scan speeds.

For instance, on the PEKK sample shown in Fig. 19, the measured layer thickness $\Delta h$ is $160 \mu \mathrm{m}$, but lower z-shift values could not be used to ensure re-melting of previous layers because of the thermal deformation of the specimen edges that provoked contact with the spread knife. In turn, a $180 \mu \mathrm{m}$ z-shift was used, which was not sufficient to ensure full re-melting of interlayer zones.

Oncoming developments will focus on the galvanic head system and software with the objective of ensuring more stable scan speeds all along the fusion paths, for limiting overheating effects and associated thermal deformations.

\section{Conclusion}

The use of combined experimental and numerical developments has been shown to provide useful information concerning laser-matter coupling, molten polymer characteristics and damage thresholds during the SLS process. For the two polymer powders investigated on a specifically designed SLS set-up, transmitted power measurements allowed determining the powder transmission law, which was used as a volume heat source for numerical calculations. Such numerical calculations were shown to reproduce correctly experimental fusion depths with the use of a $K=0.4$ absorption coefficient, which indicates that most of the incident laser light (60\%) is either reflected or diffused in the powder bed. Last, time-temperature profiles were numerically estimated on the PEKK powder, and allowed us determining thermo-oxidative degradation thresholds. In turn, this numerical approach allowed selecting adequate parameters for limiting degradation, and ensuring optimum fusion depths.

In the last stage, the manufacturing of additive layers was shown to be problematic due to non-constant scan speed values along the fusion paths. This provoked local overheating and extensive deformations that impeded a full densification of the SLS parts.

\section{Acknowledgments}

Authors would like to thank the whole FADIPLAST consortium for helpful discussions, and the French Ministries of Economy, Industry and employment (Direction of Competitiveness and Services) for financial support. They would like also to thank the following ENSAM students: Boris Valkov, François Sauvage, Cyrielle Louis, Benoit Leleux and Guillaume Gentil, for their active participation in the experimental work.

\section{References}

Bonaccina, C., Comini, G., Fasano, A., Primicerio, M., 1973. Numerical solution of phase-change problems. Int. J. Heat Mass Transf. 16, 1825-1832.

Childs, T.H.C., Berzins, M., Ryder, G.R., 1999. Selective laser sintering of an amorphous polymer: simulations and experiments. Proc. Inst. Mech. Eng. Part B J. Eng. Manuf. 213 (4), 333-349.

Defauchy, D., 2013. Simulation Du Procédé De Fabrication Directe De Pièces Thermoplastiques Par Fusion Laser De Poudre (Ph.D. doctorate dissertation). Arts et Métiers Paris-Tech.

Dong, L., Makradi, A., Ahzi, S., Remond, Y., 2009. Three-dimensional transient finite element analysis of the selective laser sintering process. J. Mater. Process. Technol. 209 (2), 700-706.

Dumoulin, E., 2014. Fabrication Additive De Pièces En Polymères Thermoplastiques Hautes Performances Et En Polyamide 12 Par Le Procédé De Frittage Sélectif Par Laser (Ph.D. doctorate dissertation). Mines Paris-Tech.

Dupin, S., 2012. Etude Fondamentale De La Transformation Du Polyamide 12 Par Frittage Laser: Mécanismes Physico-Chimiques Et Relations Microstructures-Propriétés (Ph.D. doctorate dissertation). INSA de Lyon.

Franco, A., Romoli, L., 2012. Characterization of laser energy consumption in sintering of polymer-based powders. J. Mater. Process. Technol. 212, 917-926.

Frenkel, J., 1945. Viscous flow of crystalline bodies under the action of surface tensions. J. Phys. 9, 385-391.

Goodridge, R.D., Tuck, C.J., Hague, R.J.M., 2012. Laser sintering of polyamides and other polymers. Prog. Mater. Sci. 57, 229-267.

Hussein, A., Hiao, L., Yan, C., Everson, R., 2013. Finite element simulation of the temperature and stress fields in single layers built without support in selective laser melting. Mater. Des. 52, 638-647.

Kruth, J.P., Levy, G., Klocke, F., Childs, T.H.C., 2007. Consolidation phenomena in laser and powder-bed based layered manufacturing. Ann. CIRP 56 (2), 730-759.

Peyre, P., Neveu, R., Aubry, P., Fabbro, R., Longuet, A., 2008. Analytical and numerical modelling of the direct metal deposition laser process. J. Phys D: Appl. Phys. 41 $1-10$.

Pham, D.T., Dotchev, K.D., Yusoff, W.A.Y., 2008. Deterioration of polyamide powder properties in the laser sintering process. Mech. Eng. Sci. 222, 2163-2176.

Schmidt, M., Pohle, D., Rechtenwald, T., 2007. Selective laser sintering of PEEK. Ann. CIRP 56 (1), 205-208.

Tolochko, N.K., Khlopkov, Y.V., Mozzharov, S.E., Ignatiev, M.B., Laoui, T., 2000 Absorptance of powder materials suitable for laser sintering. Rapid Prototyp. J. 6 (3), 155-161. 